\title{
Doing Better with What We've Got: Implementation Science in Integrative Health Amidst New Attention to Health Services Research
}

\author{
John Weeks
}

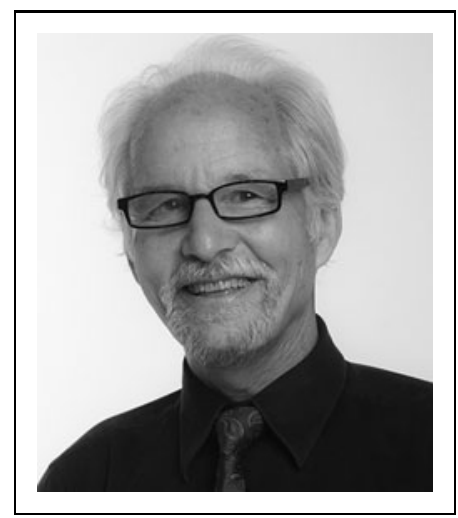

$\mathbf{T}$ HE POINT OF THIS column is to focus attention on the convergence of two movements in research activity. On the one hand, the chief scientific conferences in integrative health and medicine show an ascending interest in implementation science (IS) and, more generally, in policy and associated health services research. In October 2018, for instance, the conference of the Society of Integrative Oncology, "From Research to Practice Applications," included a plenary featuring a federal scientist ${ }^{1}$ who is driving implementation science at the National Cancer Institute.

Implementation science's "study of methods to promote the integration of research findings and evidence into healthcare policy and practice", 2 will see further exposure at the May 2019 International Congress on Complementary Medicine Research in Brisbane, Australia. ${ }^{3}$ Conference planners imbedded a morning plenary on IS inside a program bricked with policy-related content. A month later, in Burlington, Vermont, the Society for Acupuncture Research jumps with both feet into the translational terrain. Sessions featuring insurers, hospital administrators, elected officials, and analysis of existing implementation models populate a conference themed "Acupuncture Research, Health Care Policy, and Community Health-Closing the Loop." 4 Something is afoot.

This train of activity and interest inside the integrative health field may gather steam by intentionally dovetailing with activity from multiple foundations and government agencies to energize a locomotive that can pull IS forward. In November 2018, the USA National Academy of Medicine (NAM) — which views itself as having global impact ${ }^{5}$ issued a report ${ }^{6}$ directed at jacking up the resources, power, and influence for health services research (HSR). The current vertical hierarchy guiding resource allocation in research suffers from an interprofessional deficit, poorly respecting inputs of multiple research disciplines. HSR has been relegated to a lower tier position that arguably values the status quo over good sense. After all, with medical payment and delivery non-systems in such evident shambles all around us, one might have hoped by now someone might call out hey wait, maybe we should invest more in doing better with what we have and know now.

Inside the 83 pages of the prosaically-titled "The Future of Health Services Research: Advancing Health Systems Research and Practice in the United States," ${ }^{\circ}$ HSR championsamong them major players like the Robert Wood Johnson Foundation-mount what is effectively a peasant revolt to demand respect for such common sense. The moment is viewed as "a pivotal time in thinking about federal support for health services research...there is a policy window of opportunity that is opening." "6 Yet the call for resources continues to be self-esteem challenged in a Rodney Dangerfield sort of way. The authors begin by bowing to the basic scientists who lord over resource distribution. HSR's skimpy 3\% of global research budget is a battering reminder of their manifestly lower worth, if measured in dollars. ${ }^{6}$ Can't get no respect.

Yet, imagine if for the next two decades even $20 \%$ of research funding targeted doing better with the evidenceinformed tools we have. Might enhancing patient and practitioner experience, bettering population health, and lowering per capita costs - the quadruple aim of valuebased medicine-be results if funders turned attention to creating optimal results with the evidence-informed means currently at our collective disposal? At the NAM workshop, former American Hospital Association chair, Jonathan Perlin, MD, PhD, declared against the field's Dangerfield-esque present lack of funding respect: "[HSR] should not be the fourth kind of research that is considered but the first... because medical research makes no sense if it isn't disseminated in a way that reaches every American and helps with their health." 6 
Among the under-explored tools that such enhanced self-esteem and expanded budget could prioritize are the contributions from evidence-informed complementary and integrative health products, practices, and practitioners. Such engagement is urged globally through a call in the WHO Traditional Medicine Strategic Plan 2014-2023 to examine the role of such practices in meeting the goal of universal health care. ${ }^{7}$ Government initiatives in China, ${ }^{8}$ India, ${ }^{9}$ and elsewhere are fueled by a vision of a future health care with more optimal use of traditional and complementary practices and practitioners. In North America, pain ${ }^{10}$ and cancer guidelines ${ }^{11}$ include complementary and integrative approaches. These beg for investment in exploration of requisite shifts in practice. The opioid crisis in the US provoked inclusion of nonpharmacologic approaches ${ }^{12}$ in the national response strategy. Multiple state-based pilots backed by assembled evidence for complementary treatment have commenced. ${ }^{13,14}$ The growing evidence base over the last two decades-with still more questions than answers - has nonetheless created a foundation for a present focus on implementation and inclusion.

Notably, two decades ago, the Eurocentric world's single most powerful funder of research in complementary and integrative health was charged with a powerful implementation agenda. The first directive of the 1998 mandate from the US Congress to the National Institutes of Health to establish what is now the National Center for Complementary and Integrative Health (NCCIH), Section (c), read as follows: "the Director of the Center shall, as appropriate, study the integration of alternative treatment, diagnostic and prevention systems, modalities, and disciplines with the practice of conventional medicine as a complement to such medicine and into health care delivery systems in the United States." 15 It's a charge that would have been quite at home at the NAM workshop on HSR. To underline Congress' practical frame of mind, Section (e) of the same mandate specifically asks the Center to examine the impact of licensed disciplines with which Congress was concerned, such as acupuncture, chiropractic, naturopathic medicine, and massage therapy. In Section (f) Congress got further into micromanaging the $\mathrm{NIH}$, providing numbered priorities for the types of research the new center should prioritize: (1) outcomes research and investigations, (2) epidemiologic studies, (3) health services research-and only then (4) basic science research, (5) clinical trials, and (6) other appropriate research. The NAM workshop attendees, Perlin included, would likely have been ecstatic with such a charge.

The record has shown that such Congressional efforts to micromanage a big ship on a different trajectory did not alter the inertia of the top-down, basic science/clinical trials power players in grant-getting. That said, some of the evidence creating the present supportive context for IS, noted above, came via the clinical trials funded by NCCIH and other NIH branches. Moreover, the NCCIH in recent years has shown signs, in partnerships with the Veterans Administration and Department of Defense, for instance, of a more real world bent. ${ }^{16,17}$ With a recent transition in leadership ${ }^{18}$, perhaps the time is right for re-engaging Congressional intent and directing a substantial percentage of resources toward implementation strategies. The NAM report's note of present Congressional interest in better integrating the work of the health services-focused Agency for Healthcare Research and Quality with that of the NIH is a principal motivator for the workshop providers.
In a recent commentary, ${ }^{19}$ Amie Steel, ND, PhD, MPH and Jon Adams, MA, PhD, two of the Australians planning the May 2019 ICCMR with its elevation of implementation science, examined some of the issues with co-author Karen Rapport, $\mathrm{PhD}$, that might face the NCCIH or other agencies should they up their investment in implementation. A familiar challenge: "The disparate nature of complementary health care professions (both within and across disciplines) render such reliance upon infrastructure ill-suited, with IS applications in complementary medicine requiring an innovative rethink." 19 The NAM report on HSR similarly falls short of imagining the outcomes of optimal use of these licensed disciplines if patients are directed toward the use of community-based providers. For instance, these practitoners are not likely to be integrated into electronic health platforms, and even if so, the boxes to check will likely be misfits. Still, the Australian team pleas for recognition of the public interest in complementary and integrative approaches: "The growing IS field needs to consider how to focus its energies on all available healthcare options currently utilized by the general population.,"19

When major medical stakeholders gathered for the workshop that led to the recent NAM tome promoting HSR, they were greeted with a blunt directive from Michael McGinnis, $\mathrm{MD}$, the NAM executive officer: "We've gathered here to discuss solutions - and the science of bringing solutions to practice is through health services research." Integrative health leaders were notably not in the room, and their presence is not noted in the report. Yet, as multiple guidelines and policy directives have concluded, integrative strategies are part of the solutions to which McGinnis refers. A chunk of HSR resources would be useful if focused on examining the evidence-informed integrative potential.

Submissions to the philanthropically-backed JACM Special Issue on Multi-Modal Approaches in Integrative Health: Whole Persons, Whole Practices, Whole Systems - to be published in the first quarter of 2019-underscore the need for such resources: the state of Oregon's efforts to include nonpharmacological practitioners in pain treatment; the Veterans Administration's massive campaign to transform to a "whole health model;" development of an integrative pain center at a major safety net hospital; implementing an inpatient acupuncture service, and much more. Evidence mounting for the multiple values of group-delivered services - the subject of a JACM Special Issue on Innovation in Group-Delivered Services (still open for submissions until February 28, 2019) -is another area begging for implementation research on both payment and delivery models.

These two trains of action-in the integrative health field and in the NAM call to action for HSR - are already running down the same track, and in the same direction. The advocates for more resources for researching real world uptake of existing research would advance their goals by reaching across to their integratively minded colleagues and exploring these newer, evidence-informed, integrative models. It would serve the integrative health research community to connect to the promoters of HSR and hitch their wagons to the more powerful engine. The scientific conferences in complementary and integrative health, noted at the beginning of this editorial, indicate that the field's researchers are awakening to these emerging opportunities. 


\section{References}

1. Society for Integrative Oncology. Integrative Oncology: From Research to Practical Applications 2018 Conference Program. Online document at: https://integrativeonc.org/ program/agenda, accessed November 29, 2018.

2. Dearing J, Kee K. Historical roots of dissemination and implementation science. In: Brownson RC, Colditz GA, Proctor EK, eds. Dissemination and Implementation Research in Health: Translating Science to Practice. New York: Oxford University Press, 2012:47-61.

3. ICCMR. ICCMR 2019: $14^{\text {th }}$ International Congress on Complementary Medicine Research Program. Online document at: http://iccmr2019.com/program/, accessed November 29, 2018.

4. Society for Acupuncture Research. Acupuncture Research, Health Care Policy \& Community Health: Closing the Loop. Online document at: https://www.acupuncture research.org/assets/docs/C2019_docs/SAR\%20Conference \%20Flier-1.pdf, accessed November 29, 2018.

5. National Academy of Medicine. About the National Academy of Medicine. Online document at: https://nam.edu/about-thenam/, accessed November 29, 2018.

6. Whicher C, Rosengren K, Siddiqi S, et al. The Future of Health Services Research: Advancing Health Systems Research and Practice in the United States. Washington, DC: National Academy of Medicine, 2018.

7. World Health Organization. WHO Traditional Medicine Strategic Plan 2014-2023. Online document at: https:// www.who.int/medicines/publications/traditional/trm_strategy 14_23/en/, accessed November 29, 2018.

8. Weeks J. Chinese TCM renaissance and the global movement for integrative health and medicine. J Altern Complement Med 2017;23:79-81.

9. Ministry of AYUSH, Government of India. About the Ministry of AYUSH. Online document at: http://ayush.gov.in/ about-us/about-the-ministry, accessed November 29, 2018.

10. Qaseem A, Wilt T, McLean R, et al. Noninvasive treatments for acute, subacute, and chronic low back pain: A clinical practice guideline from the American college of physicians. Ann Intern Med 2017;166:514-530.

11. Lyman $G$, Greenlee $H$, Bohlke $K$, et al. Integrative therapies during and after breast cancer treatment: ASCO endorsement of the SIO clinical practice guideline. J Clin Oncol 2018;36:2647-2655.
12. Weeks J. Did the National Academy of Medicine consider integrative in their opioids report? Online document at: https://www.integrativepractitioner.com/topics/ analysis/national-academy-medicine-consider-integrativeopioids-report, accessed November 29, 2018.

13. Davis R, Badger G, Valentine K, et al. Acupuncture for chronic pain in the vermont medicaid population: A prospective, pragmatic intervention trial. Glob Adv Health and Med 2018;7:2164956118769447.

14. Ross C. As the opioid crisis grows, states are opening Medicaid to alternative medicine. Online document at: https://www.statnews.com/2018/01/17/medicaid-opioidsalternative-medicine/, accessed November 29, 2018.

15. Weeks J. How NCCAM's "Real World" Congressional Mandate is Optimal for NCCAM's 2010-2015 Strategic Plan. Online document at: http://theintegratorblog.com/index .php?option=com_content $\&$ task $=$ view $\&$ id $=606 \&$ Itemid $=189$, accessed November 29, 2018.

16. Weeks J. The new USA NIH strategic plan for complementary and integrative health: Interview with Josephine Briggs, MD: Director, national center for complementary and integrative health (part 1). J Altern Complement Med 2016;22:680-683.

17. Weeks J. The new USA NIH strategic plan for complementary and integrative health: Interview with Josephine Briggs, MD: Director, national center for complementary and integrative health (part 2). J Altern Complement Med 2016;22:765-767.

18. National Center for Complementary and Integrative Health. NIH names Dr. Helene Langevin director of the National Center for Complementary and Integrative Health. Online document at: https://nccih.nih.gov/news/press/LangevinNCCIH-Director-Selected, accessed November 29, 2018.

19. Steel A, Rapport F, Adams J. Towards an implementation science of complementary health care: Some initial considerations for guiding safe, effective clinical decisionmaking. Adv Integr Med 2018;5:5-8.

Address correspondence to: John Weeks johnweeks-integrator.com Seattle, WA 98116

E-mail: jweeks.jacm@gmail.com 